\title{
Exploratory Remote Sensing Studies to Determine the Mineralization Zones around the Zarshuran Gold Mine
}

\author{
Adel Shirazy \\ Shahrood University of \\ Technology \\ Shahrood, Iran
}

\author{
Aref Shirazi \\ AmirKabir University of \\ Technology \\ Tehran, Iran
}

\author{
Saeed Heidarlaki \\ Shahrood University of \\ Technology \\ Shahrood, Iran
}

\author{
Mansour Ziaii * \\ Shahrood University of \\ Technology \\ Shahrood, Iran
}

\begin{abstract}
Zarshuran gold mine is located in Takab city and West Azarbaijan province. Due to the importance of remote sensing in the identification of mineralization and alterations in mineral areas, remote sensing studies were carried out around the gold mine. The purpose of these studies was to identify mineralization zones around the mine area. In this study, due to the suitability of Aster Images to identify copper alterations various methods of remote sensing such as false color combinations (FCC) and spectral angle mapper (SAM) for mapping altrations and promising regions were used. Finally, areas with mineralization and alteration were presented as maps.
\end{abstract}

Keywords: Remote Sensing; FCC; SAM; Aster; Gold

\section{INTRODUCTION}

We Remote sensing is the acquisition of information about an object or phenomenon without making physical contact with the object and thus in contrast to on-site observation. Remote sensing is used in numerous fields, including geography, land surveying and most Earth Science disciplines (for example, hydrology, ecology, oceanography, glaciology, geology); it also has military, intelligence, commercial, economic, planning, and humanitarian applications [1] [2].

In current usage, the term "remote sensing" generally refers to the use of satellite- or aircraft-based sensor technologies to detect and classify objects on Earth, including on the surface and in the atmosphere and oceans, based on propagated signals (e.g. electromagnetic radiation). It may be split into "active" remote sensing (i.e., when a signal is emitted by a satellite or aircraft and its reflection by the object is detected by the sensor) and "passive" remote sensing (i.e., when the reflection of sunlight is detected by the sensor) [3] [4] [5].

Remote sensing is one of the methods that can be used to separate surface anomalies from the field by detecting alterations and target minerals. In the early stages of regional exploration, it is possible to identify mineralization and alteration by using the classic and modern statistical methods on the geochemical data in the study region [6] [7]. The combination of remote sensing results and geochemical statistical studies can provide more reliable results [8]. Also, initial exploratory studies include economic studies and mineral processing in the region. Statistical and geochemical studies are the basis of these studies [9].

All material on each page should fit within a rectangle of $18 \mathrm{x}$ $23.5 \mathrm{~cm}$ (7" x 9.25"), centered on the page, beginning $2.54 \mathrm{~cm}$ (1") from the top of the page and ending with $2.54 \mathrm{~cm}(1 ")$ from the bottom. The right and left margins should be $1.9 \mathrm{~cm}$ (.75"). The text should be in two $8.45 \mathrm{~cm}(3.33 ")$ columns with a $.83 \mathrm{~cm}(.33 ")$ gutter[10].

\section{METHODOLOGY AND DATASET}

\subsection{Geolocation of Study Area}

The Zarshuran mineral zone is located in West Azarbaijan province of Iran and on geological sheet of Takht-e-Soleyman (on sclae 1:100,000). The Takht-e-Soleyman sheet covers parts of Zanjan, West Azarbaijan and East Azarbaijan provinces. The Takht-e-Soleyman sheet is part of the 1: 250000 geological map of the Takab rectangle between the eastern longitude $47^{\circ} 00^{\prime}$ and $47^{\circ} 30^{\prime}$ and the north latitude $36^{\circ} 30^{\prime}$ 'to $37^{\circ} 00^{\prime}$. The quadrilateral coordinates of the studied area are presented in Table 1. Due to its location in the Takab metallurgical province and the location of the AlborzAzarbaijan, Iran Central and Sanandaj-Sirjan construction zones, this area has a lot of mineralization diversity. The most important mineralization in this area is the lead and zinc mineralization (Anguran, Alam Kandy and Arpachai) and gold mineralization (Zarshuran, Aghdare and Tozlar). The study area of this project is located between Zanjan and East Azarbaijan provinces around the Zarshuran gold mine. Geolocation of study area in Iran map is shown in figure 1.

Table 1. Geographical coordinates of study area

\begin{tabular}{|c|c|c|}
\hline \multicolumn{2}{|c|}{ Geographical Coordinates } & \multirow{2}{*}{} \\
\cline { 1 - 2 } Latitude (Y) & Longitude (X) & है \\
\hline $36^{\circ} 40^{\prime} 49^{\prime \prime}$ & $47^{\circ} 08^{\prime} 00^{\prime \prime}$ & A \\
\hline $36^{\circ} 44^{\prime} 06^{\prime \prime}$ & $47^{\circ} 08^{\prime} 00^{\prime \prime}$ & B \\
\hline $36^{\circ} 44^{\prime} 06^{\prime \prime}$ & $47^{\circ} 12^{\prime} 03^{\prime \prime}$ & $\mathbf{C}$ \\
\hline $36^{\circ} 40^{\prime} 49^{\prime \prime}$ & $47^{\circ} 12^{\prime} 03^{\prime \prime}$ & $\mathbf{D}$ \\
\hline
\end{tabular}




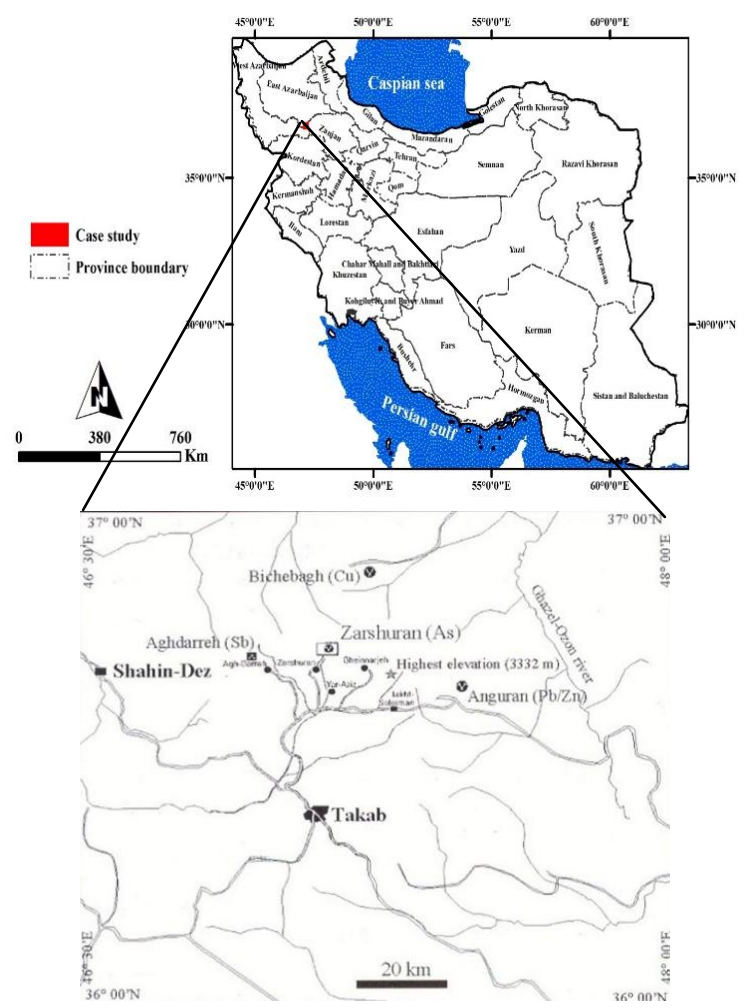

Figure 1. Geolocation of study area in Iran map

\subsection{Satellite Remote Sensing Data}

In this study, the image of the ASTER Satellite Sensor was used. ASTER (Advanced Spaceborne Thermal Emission and Reflection Radiometer) is a high resolution imaging instrument that is flying on the Terra satellite [11]. ASTER will obtain detailed maps of land surface temperature, emissivity, reflectance and elevation of the Earth.

ASTER has three sensors to measure and record the reflected and emitted Electromagnetic Radiation (EMR). They are working in different wavelength regions the Visible and Near Infrared (VNIR) between 0.52 and $0.86 \mu \mathrm{m}$, Short Wave Infrared (SWIR) between 1.6 and $2.43 \mu \mathrm{m}$, and Thermal Infrared (TIR) between 8.125 and $11.65 \mu \mathrm{m}$. ASTER data consists of 14 spectral bands 3 VNIR, 6 SWIR, and 5 TIR with 15,30 , and $90 \mathrm{~m}$ spatial resolution, espectively [12]. The VNIR, SWIR and TIR wavelength regions provide complementary data for lithological mapping [13].

Geometric corrections were made using the satellite $\mathrm{ETM}^{+}$ satellite image on the study area image. In order to ensure the results, IAR Reflectance radiometric corrections were applied to the region image and the results for applying different types of processes were introduced into ENVI software[5; 14].

Please use a 9-point Times Roman font, or other Roman font with serifs, as close as possible in appearance to Times Roman in which these guidelines have been set. The goal is to have a 9-point text, as you see here. Please use sans-serif or non-proportional fonts only for special purposes, such as distinguishing source code text. If Times Roman is not available, try the font named Computer Modern Roman. On a
Macintosh, use the font named Times. Right margins should be justified, not ragged [10].

\subsection{False Color Combinations Method}

The importance of displaying the color combination of images in remote sensing can be considered due to their effectiveness in visual interpretation of various effects. One of the effective methods for identifying and separating various geological units is the false color combination (FCC) method [15].

The false color combination is a combination of three different bands combined in red, green, and blue (RGB) colors. If the combined bands of red, green, and blue wavelengths are the visible spectrum of electromagnetic spectrum, the resulting image will be a true color combination. If a different combination of red, green and blue bands or other bands of the electromagnetic spectrum is used, a false color image will be obtained that is not similar to the surface of the earth and its colors [16].

In making false color combinations it is better to use bands that have less correlation. Since the interaction of different wavelengths of electromagnetic energy is different in dealing with rock units, the sensitivity of the human eye to minor changes in color is much greater than its sensitivity to changes in black and white images. Choosing the best band combination depends on the target [17].

Three images can be combined to make the images visible for viewing in three blue, green, and red wavelengths (original RGB color combinations). In this study, this combination has been used to display several images in a single image and simultaneously display different information from a single point [18].

Calculation of the optimum index factor amount (OIF) is required to obtain the best false color combination (OIF of the higher color combinative with more information). The formula below shows the OIF calculation method [19].

$$
O I F=\frac{\sum_{k=1}^{3} S_{k}}{\sum_{j=1}^{3} r_{j}}
$$

In formula $1: S_{k}$ is the standard deviation of the $k$ band, $r_{j}$ is the two-band correlation coefficient of the three-band combination [20]. Sometimes visually, the false color combinations containing major information are determined by the variety of colors $[5 ; 21][10]$.

\subsection{Spectral Angle Mapper (SAM) Method}

Spectral angle mapping (SAM) method is an image classification method by calculating the similarity between the image spectrum and a reference spectrum (e.g., spectral libraries) [22]. The algorithm of this method calculates the similarity between two spectra by the spectral angle between 
them [23]. In fact, by transforming the spectra into a vector in a space in the number of dimensions of the bands, the angle between the two vectors is calculated (See figure 2) [24] .

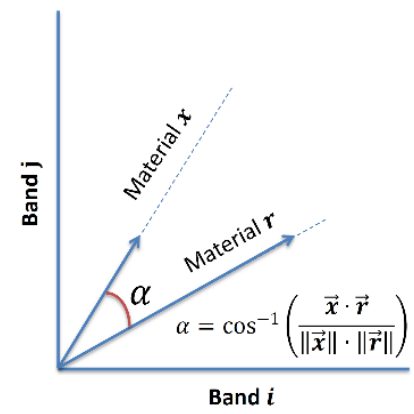

Figure. 2 Example of SAM classification in case of 2 spectral bands. Scalar product between unknown material $x$ and library sample $r$ [24].

In this method, the direction is important for calculating vectors, not length. Therefore, other factors are not considered in this method. In fact, the more the angle (between 0 and 1) is less, the more accurate it will be. If the value is 0 , the whole image is identified as the desired phenomenon. To compare a pixel, the desired pixel spectrum is plotted from the examined area with the same pixel spectrum in the laboratory (library) on two bands in a coordinate axis. Then the points are connected to the coordinate center, and the angle between the two lines is used as the pixel identification angle. If the $n$ bands are used to identify the phenomenon concerned, the following formula is used to obtain an angle[5] [25] [10].

$$
\alpha=\operatorname{Cos}^{-1}\left[\frac{\sum_{i=1}^{n b} x_{i} r_{i}}{\left(\sum_{i=1}^{n b} x_{i}^{2}\right)^{\frac{1}{2}}\left(\sum_{i=1}^{n b} r_{i}^{2}\right)^{\frac{1}{2}}}\right]
$$

In formula $3: \mathrm{nb}$ is the number of bands. unknown material $x$ and library sample $r$.

\section{RESULTS AND DISCUSSION}

\subsection{False Color Combinations Method}

One of the methods used to identify hydrothermal alterations in esters is the use of false color combinations. Al-OH bonded minerals such as kaolinite, muscovite and montmorillonite and ilite, index minerals (phylic and argillic alteration zones) have maximum reflection in the band of 4 SWIR regions. Also, minerals containing $\mathrm{Mg}-\mathrm{OH}$ such as chlorite and epidote, which are the propylitic altration zone index, have a high reflection in the ASTER spectral band of the spectral range of the SWIR. Therefore, the false color combination (FCC) 4-6-8 of the SWIR region will show the red and pink red and red and pink red argillic zones and the proplyitic alteration zones in green [26]. In the study area, phylic and argillic alterations are seen in red to pink, while the alteration stones related to propylitic alteration are green in the vicinity of the argillic-phyllic alterations (Figure 3).

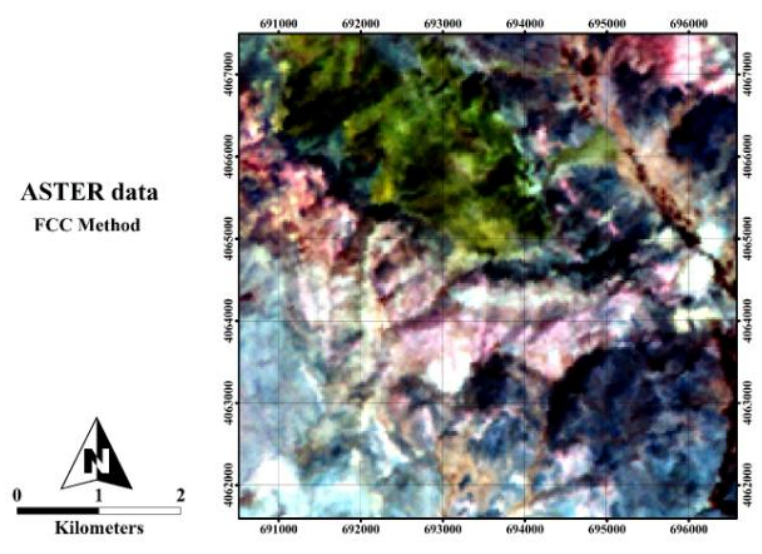

Figure 3. False color combination 4-6-8 (RGB). Phylic alteration and argillic are seen in red to pink and propylitic alterations are green.

Most deposits and minerals are closely related to geological structures, lithological units, tectonics and faults in the region. Using satellite imagery, lithological units and geological structures of the region can be identified and differentiated, which would help to identify the mineralogy and ultimately explore the deposits in them. One of the best ways to identify these structures is the use of ETM + images. The use of these images provides a good idea to identify the structure of tectonics and geological structures and rock units in the area. For the detection and separation of stone units in ETM + images, the color combination of the band 5 in the red channel and the band 3 in the green channel and the band 1 in the blue channel is the best color combination[27]. In this research, ETM + band 5, 3 and 1 were used to distinguish rock units and identify lines such as faults in the region.

The false color combination of 5-3-1 was used to display the image. As shown in Figure 4, the stone units are well separated. In Figure 5, the main faults in the area are well identified. By matching the image from the color combination 5-3-1 with the geologic map of the area, the accuracy of the results obtained from the processing of ETM + images is confirmed for the identification and separation of rock units and lineaments in the region.

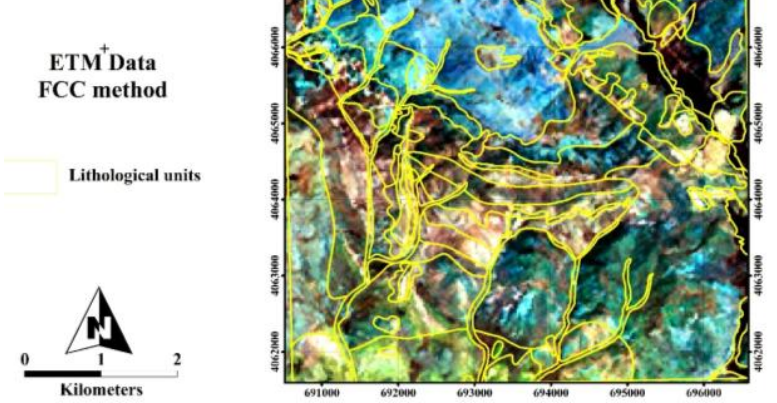


Figure 4. Map of the division of linguistic units of the study area using the false color combination of the 5-3-1 band of the ETM + sensor.

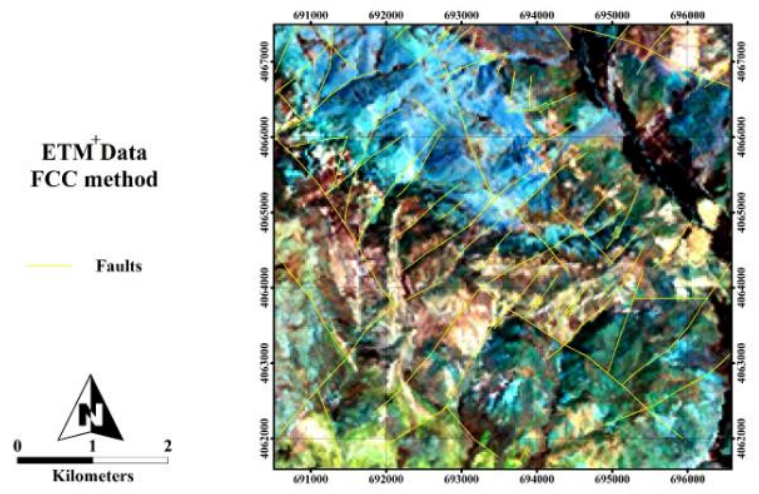

Figure 5. Identification map of the lines (faults) of the study area using the false color combination of the 5-3-1 band of the ETM+ sensor.

\subsection{Spectral Angle Mapper (SAM) Method}

Spectral analysis of ASTER images can be a very useful tool for identifying various types of alterations such as argillic, advanced argillic, sericitic, propylitic, silicification and iron oxides. In practice, the ability of this tool depends on a large number of factors, including:

- Presence of vegetation: vegetation strongly influences spectral properties of alteration areas.

- Effect of surface coating system: Small systems such as mesothermal veins and mild sulfide systems are often smaller than the spatial resolution of ASTER images.

- Host rock: Spectral analysis in volcanic systems is a very useful tool, so that in these rocks the alteration areas are in contrast to the surrounding rocks and can be distinguished. In these systems, even very tight target areas can be identified.
The main advantage of this method, among the methods of satellite data classification, is the ease and speed of mapping based on the spectral similarity between the spectrum of the problem and the reference spectrum. As you can see in Figure 6, various minerals, which indicate hydrothermal alterations and iron oxide and silica alterations are identified separately.

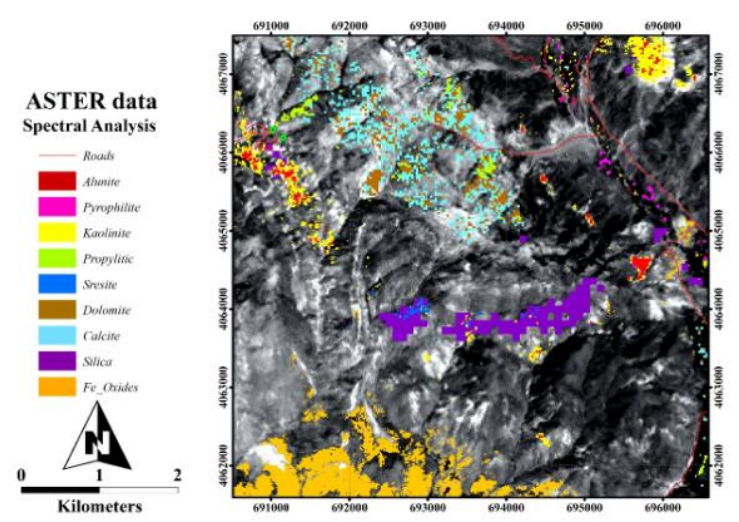

Figure 6. Map of alterations in the study area using the SAM method

\section{CONCLUSION}

- Considering the importance of remote sensing in identifying mineralization and alterations in mineral areas, this study was carried out in the studied area under the name of Zarshuran in the north of Takab in West Azarbaijan province in northwest.

- In these studies, after corrections made on satellite images, methods such as false color combination, band ratio and spectral analysis method have been used.

- The result of these surveys is the identification of alterations and mineralization of the region, as presented in Figures 3 to 6 . The results indicate that there are several promising regions, most of them in the west and northwest of the region. The results of this research can be used to promote the mineral exploration project around the Zarshuran mine.

\section{REFERENCES :}

[1] Schott, J. R. (2007). Remote sensing: the image chain approach: Oxford University Press on Demand.

[2] Guo, H., Huang, Q., Li, X., Sun, Z., \& Zhang, Y. (2013). Spatiotemporal analysis of urban environment based on the vegetation-impervious surface-soil model. Journal of Applied Remote Sensing, 8(1), 084597.

[3] Zhang, X., Pazner, M., \& Duke, N. (2007). Lithologic and mineral information extraction for gold exploration using ASTER data in the south Chocolate Mountains (California). ISPRS Journal of Photogrammetry and Remote Sensing, 62(4), 271-282.

[4] Robert, A. S. (2007). Remote sensing: Models and methods for image processing. By Elsevier Inc. All rights reserved, p300-304. 
[5] Shirazi, A., Hezarkhani, A., Shirazy, A., \& Shahrood, I. (2018). Remote Sensing Studies for Mapping of Iron Oxide Regions, South of Kerman, IRAN. International Journal of Science and Engineering Applications, 7(4), 45-51.

[6] Shirazi, A., Hezarkhani, A., Shirazy, A., \& Shahrood, I. (2018). Exploration Geochemistry Data-Application for Cu Anomaly Separation Based On Classical and Modern Statistical Methods in South Khorasan, Iran. International Journal of Science and Engineering Applications, 7, 39-44.

[7] Shirazi, A., Shirazy, A., Saki, S., \& Hezarkhani, A. (2018). Geostatistics Studies and Geochemical Modeling Based on Core Data, Sheytoor Iron Deposit, Iran. Journal of Geological Resource and Engineering, 6, $124-$ 133.

[8] Alahgholi, S., Shirazy, A., \& Shirazi, A. (2018). Geostatistical Studies and Anomalous Elements Detection, Bardaskan Area, IRAN. Open Journal of Geology, 8(07), 697.

[9] Khakmardan, S., Shirazi, A., Shirazy, A., \& Hosseingholi, H. (2018). Copper Oxide Ore Leaching Ability and Cementation Behavior, Mesgaran Deposit in IRAN. Open Journal of Geology, 8(09), 841.

[10] Shirazi, A., Shirazy, A., \& Karami, J. (2018). Remote Sensing to Identify Copper Alterations and Promising Regions, Sarbishe, South Khorasan, Iran. International Journal of Geology and Earth Sciences, 4(2), 36-52.

[11] Arivazhagan, S., \& Anbazhagan, S. (2017). ASTER Data Analyses for Lithological Discrimination of Sittampundi Anorthositic Complex, Southern India.

[12] Obata, K., Tsuchida, S., Yamamoto, H., \& Thome, K. (2017). Cross-Calibration between ASTER and MODIS Visible to Near-Infrared Bands for Improvement of ASTER Radiometric Calibration. Sensors, 17(8), 1793.

[13] Amer, R., Kusky, T., \& Ghulam, A. (2010). Lithological mapping in the Central Eastern Desert of Egypt using ASTER data. Journal of African Earth Sciences, 56(2-3), 75-82.

[14] Padró, J.-C., Pons, X., Aragonés, D., Díaz-Delgado, R., García, D., Bustamante, J., . . . Cristóbal, J. (2017). Radiometric Correction of Simultaneously Acquired Landsat-7/Landsat-8 and Sentinel-2A Imagery Using Pseudoinvariant Areas (PIA): Contributing to the Landsat Time Series Legacy. Remote Sensing, 9(12), 1319.

[15] Abdelaziz, R., El-Rahman, Y. A., \& Wilhelm, S. (2018). Landsat-8 data for chromite prospecting in the Logar Massif, Afghanistan. Heliyon, 4(2), e00542.

[16] Masoumi, F., Eslamkish, T., Honarmand, M., \& Abkar, A. A. (2017). A Comparative Study of Landsat-7 and Landsat-8 Data Using Image Processing Methods for Hydrothermal Alteration Mapping. Resource Geology, 67(1), 72-88.

[17] Yao, K., Pradhan, B., \& Idrees, M. O. (2017). Identification of rocks and their quartz content in gua musang goldfield using advanced spaceborne thermal emission and reflection radiometer imagery. Journal of Sensors, 2017.

[18] Hereher, M. E., \& Abdullah, S. E. (2017). Lithologic mapping of Aja granitic batholiths, Ha'il, Saudi Arabia, using remote sensing. Arabian Journal of Geosciences, 10(14), 313.

[19] Razmi, M., Asgari, H. M., Sohrab, A. D., Nazemosadat, S. M. J., \& Khazaei, S. H. (2017). Monitoring oscillations coastline of Dayyer city during the El Niño and La Niño using OIF utility index.

[20] Abbaszadeh, M. (2010). Mapping hydrothermal alterations using ASTER images in Parkam area, Kerman. GEOSCIENCES, 78.

[21] Hooshyari, N. (2005). Separation of alteration zones in relation to possible mineralization of gold and copper Zofre area using satellite data ASTER. (BSc), Isfahan University of Technology.

[22] Asadzadeh, S., \& de Souza Filho, C. R. (2016). A review on spectral processing methods for geological remote sensing. International journal of applied earth observation and geoinformation, 47, 69-90.

[23] Hasan, E., Fagin, T., El Alfy, Z., \& Hong, Y. (2016). Spectral Angle Mapper and aeromagnetic data integration for gold-associated alteration zone mapping: a case study for the Central Eastern Desert Egypt. International Journal of Remote Sensing, 37(8), 1762-1776.

[24] Markovskiy, N. (2014). Drop-in Acceleration of GNU Octave.

[25] Esmaeeli, M., Tabaee, M., \& Asadiharooni, H. (2012). Remote Sensing Study (ASTER \& TM) and Geology of Southwest Meyme Iron Ore Deposit, IRAN. Paper presented at the 31st Symposium of Geosciences, Tehran, IRAN.

[26] Alimohammadi, M., Alirezaei, S., \& Kontak, D. J. (2015). Application of ASTER data for exploration of porphyry copper deposits: A case study of Daraloo-Sarmeshk area, southern part of the Kerman copper belt, Iran. Ore Geology Reviews, 70, 290-304. 
[27] Sadeghi, B., Khalajmasoumi, M., Afzal, P., Moarefvand, P., Yasrebi, A. B., Wetherelt, A., . . Ziazarifi, A. (2013). Using ETM+ and ASTER sensors to identify iron occurrences in the Esfordi 1: 100,000 mapping sheet of Central Iran. Journal of African Earth Sciences, 85, 103-114. 